The responsibility of the building and running of those hospitals and the right expenditure of those vast sums is enormous. If mistakes are made, through insufficient care, to solve the problem rightly, it cannot, unfortunately, be easily undone. We have gone in this respect on wrong lines in England, I believe, and the unsound in mind are in consequence not all getting the best done for their maladies. The United States and Canada would do well to make further inquiries before they follow our example.

THE SYMPTOMATOLOGY OF RENAL TUMORS; A STUDY OF SEVENTY-FOUR CASES FROM THE MASSACHUSETTS GENERAL HOSPITAL.*

By J. DELlinger barney, M.D., boston,

Genito-Urinary Surgeon to Out-Patients, Massachusetts General Hospital; Assistant in Genito-Urinary Surgery, Harvard Medical

Even a hasty glance at medical literature, recent and old, shows that neoplasms of the kidney have had their full share of consideration. Garceau's admirable monograph, the monumental work of Albarran and Imbert, and the mass of statistical material contributed by others might lead us to think that the last word had been said, and that an early diagnosis was always possible. That such is not the case most of us know, but since, as we shall see, the patient may have his first intimation of the disease unly after it has progressed beyond operative limits, we find ourselves in a situation which, in some respects, cannot be altered.

Under these circumstances, the writer makes bold to contribute his mite, in the hope that if it serves no other purpose, it will at least call attention to the gravity of the situation and to some of its difficulties.

That renal tumors are somewhat infrequent is shown by the fact that from the early eighties to the present time the clinical records of the Massachusetts General Hospital contain only 74 cases proved by operation or autopsy. This series does not, however, include many neoplasms of the kidney accidentally discovered at the autopsy table and which gave no hint of their presence during life.

The list comprises 27 hypernephromata, 7 sarcomata, 7 carcinomata, 3 adenomata, and 1 endothelioma. The remaining 24 , in the absence of microscopic examination, must remain unclassified. It is seen that, as usual, the hypernephroma occurs most often. The diagnosis of carcinoma in 7 cases leads us to believe that we have been unduly favored in this respect, but were some of the sections on which this diagnosis was based examined in the light of our present pathological knowledge, this number would probably be reduced somewhat. Also it is fair to assume that the 24 unclassified cases

* Read at the meeting of the New England branch of the American Urological Association, Hartford, Conn., Nov. 18, 1912. would group themselves in about the same proportion as the others.

In our analysis of this series we have endeavored to generalize as much as possible, believing that with certain exceptions, the symptomatology of renal neoplasms is essentially the same.

The 74 cases occurred in the white race with one exception, a negro. This is of interest, if not of importance. There were 43 males and 31 females, ranging in age from 1 year and 10 months to 66 years, the incidence being greatest in the fourth decade, with the fifth next in order. Contrary to custom, the left side was affected more often than the right, 41 against 30.

So far as could be ascertained (the estimate must necessarily be rough) the duration of symptoms pointing directly to the urinary tract or kidney ranged from a few days to over ten years. The latter figure may seem startling in the presence of a malignant growth, but is not inconsistent with our knowledge of the habits of such tumors, nor is it in disagreement with the statistics of other writers. However, in more than half the cases there were symptoms which brought the patient to the hospital within a year of their onset; in fact the greatest number (28) sought relief within six months. It is significant to find that in many the malignant nature of the disease had manifested itself in general terms long before it revealed its locality. Thus 13 patients said they had been "running down" or "losing weight" for many months or even years before the appearance of any symptoms of a local naure. It is this aspect of the situation which clips the wings of our hope and makes the early bird a rara avis.

Inquiry as to the way in which the patient became aware of his trouble shows that in forty cases the situation gradually unfolded itself by a growing sense of weakness, a slow loss of weight, a little disturbance of urination, some unaccountable dyspeptic symptoms, a fleeting pain in the loin, a change in the color of the urine, or an increase in the girth. In the remaining thirty-four the curtain was suddenly drawn, showing hematuria or tumor on a background of pain.

Loss of weight is known definitely to have occurred in 51 cases. In some it was very gradual, extending over months or even years; in others it was a question only of weeks, and often involved many pounds of flesh.

Urinary disturbances, aside from hematuria, also figure in the picture to a certain extent. Frequency, dysuria, urgency or difficulty were noted in 21 cases, but are not to be regarded as pathognomonic. In 46 , urination was said to be normal in every respect.

Nausea and vomiting, usually accompanying renal colic, but often of independent origin, were noted in 29 , and are to be regarded as significant. When not produced by renal colic, they may be accounted for by a toxemia, or even by metastases in or about the digestive organs. 
It is well known that the cardinal symptoms of renal tumor are, in order of frequency, pain, tumor and hematuria. As regards pain, a point of diagnostic value is that it may and often does come on during sleep, thus differing from the pain caused by renal calculus, and aroused by muscular activity. It may be accounted for by a passive congestion of the kidney, by pressure on nerve trunks, by the passage of clots or shreds of tissue, or by a temporary blocking of the ureter. In other features, such as intensity, duration, location and radiation, it has no special characteristies.

Hematuria, like pain, also may begin insidiously and without apparent cause. It often alternates with a clear urine, appearing late or early in the disease, and may occur but once or may be constant. Its relation to pain is important, the two often beginning simultaneously. Its duration is generally brief, its frequency and intensity variable.

An inquiry into the initial symptoms in these patients shows that pain alone occurred in 25, hematuria alone in 18, and tumor alone in 15 . Pain and tumor, and pain and hematuria sounded the alarm in six cases each, hematuria and tumor together were seen but once. That pain is an almost constant feature is shown by the fact that it occurred at some time during the course of the disease in 63 out of the 74 cases, while the patient had noticed a lump in his side 46 times, and had passed bloody urine 39 times.

Further analysis shows that from time of onset to operation or death pain was the sole symptom in 10 cases, tumor alone in 5 , and hematuria alone in 3 . On the principle that misery loves company, we find these symptoms grouping themselves together in one combination or the other so that during the course of the disease pain and tumor were the symptoms in 22 , pain, tumor and hematuria in 16, pain and hematuria in 15, and, finally, tumor and hematuria in 3 .

One patient had no symptoms in the urinary tract at any time, came to the hospital because he felt "all in," and revealed the nature of his malady only after careful physical examination.

The general condition of 30 was considered to be good, whereas in 28 it was distinctly poor, and in 15 could be called only fair. In other words, 43 cases showed the effects of the disease to a greater or less extent.

Sixty-five patients had a normal temperature at time of entrance, from which it is clear that renal growths per se cause no pyrexia.

An examination of the urine in 71 cases showed the presence of albumen, pus, casts, or blood in 61. Hematuria was observed after their admission to the hospital in 17 patients. It is thus seen that a pathological urine is the rule, but it is equally clear that in the absence of hematuria it may give no definite clue to the diagnosis. It is also noteworthy that in ten cases, all with well developed tumors, the urine, when examined, was normal in every respect. Some authors have mentioned the occasional presence of tumor cells in the urinary sediment. Such findings are conspicuous by their absence in this series. But in view of the statement of the pathologist in many of the excised kidneys, that the growth was found to have extended into the renal pelvis or ureter, one might reasonably expect the microscope to reveal tumor cells more often.

The question of increased arterial tension, especially in connection with hypernephromata, has been investigated by other writers. That it may occur has been shown by Eisendrath, Neisser and Holmes, Keen, Pfahler and Ellis, and by Ochsner. On the other hand, Eisendrath and Garceau, after careful investigation, have each concluded that it is infrequent. The meagre data furnished by the present series of cases support this view. The blood-pressure was observed in only three, one a hypernephroma, so proved by the pathologist. The patient was 54 years old, with a blood-pressure (presumably systolic) of $140 \mathrm{~mm}$. The other two cases are unclassified, but in one the clinical diagnosis was hypernephroma. The patients were 43 and 57 years of age, their blood-pressures being respectively only $120 \mathrm{~mm}$. and $135 \mathrm{~mm}$. Although this evidence is slight, it at least shows that no marked rise of blood-pressure is to be expected in such cases.

Cystoscopy and ureteral catheterization were done in but a few of these patients. In some a stream of bloody urine was seen to issue from the affected side. It seems worth while to mention briefly a case of hypernephroma, in a male, cystoscoped by the writer before operation. On the posterior bladder wall, near the fundus, was a smooth, fleshy growth, perhaps the size of a dime, with a short, thick pedicle. In the light of the subsequent operative and pathological findings it was believed that this tumor was metastatic. Garceau found only one instance of bladder metastasis in $\mathbf{1 7 6}$ cases of hypernephromata. With the hope of determining the nature of the tumor in our patient, the bladder was examined again about two weeks after operation with the Young operating cystoscope. The growth had completely disappeared, leaving behind a small scar with a sloughing base.

The x-ray, used repeatedly in our series, showed nothing of value beyond an occasional calculus, or a difference in the density or size of the two organs. We must insist, however, on the importance and even the necessity of careful examination by the cystoscope and x-ray. If the bladder presents a negative picture much valuable information can be obtained by catheterization of each ureter. By this means alone can we determine the character of the two urines, and estimate the functional capacity of each kidney, a matter of supreme importance in the consideration of nephrectomy. Also in combination with the $\mathrm{x}$-ray, the stiletted catheter or a collargol injection of the renal pelvis 
will often clinch a diagnosis, or eliminate the kidney entirely as the seat of trouble.

Convincing proof of the constancy of a palpable tumor is furnished by the statement of its presence in 65 cases. In a few the mass could not be differentiated from a mere hypertrophy of the kidney from some other cause. In the large majority its shape, nodularity, hardness, immobility, and, in some cases, enormous size, left no doubt as to its nature. Tenderness is not a constant feature, as shown by the fact that it was mentioned by the patient before entrance only fifteen times, and was elicited during the course of the physical examination only 27 times.

In view of the known tendency of renal tumors, notably hypernephromata, to begin in the upper pole, and hence escape early detection, the writer wishes to emphasize the importance of examination in other than the dorsal position. The bowels should be thoroughly emptied, and the methods of renal palpation described by Guyon, and by Israel used with care. Personal experience has demonstrated many times that a kidney which cannot be felt in the ordinary dorsal attitude, is often distinctly palpable with the patient in Israel's position, i.e. lying on the sound side with the thighs flexed, the operator palpating the kidney by bimanual pressure.

In the examination of this class of cases we must be ever watchful for evidence of metastases. Lung symptoms of vague origin, gastric disturbances of apparently idiopathic nature, bone tumors of suspicious character, must always be regarded as merely the tail to the kite. In our present series such metastases were observed clinically in but eight cases, three times in the supraclavicular glands, twice in the lung, and once each in liver, spine and pelvis. The records of many cases, on the other hand, show that the growth had long since exceeded the possibilities of operation by extension along the great vessels, while in others, coming to autopsy, the liver, brain, spleen and other vital organs were found to be hopelessly involved. In his analysis of 176 cases of hypernephromata, Garceau found bone to be the favorite seat of metastases, with lungs and regional glands next in order, but with practically every other tissue offering a fertile soil.

The investigations of Guyon, Legueu, and Morris have shown that renal tumor and varicocele (especially right sided) not infrequently go hand in hand. No such companionship has been noted in this series. There were three instances of varicocele, all on the left side, none of them remarkable for size of sudden appearance, but in each case the tumor was also on the left, a point which is perhaps suggestive. In the same connection we have noted a dilatation of the abdominal veins (caput Medusae) in four cases, once on the right, thrice on the left side, while one patient was sorely afflicted with hemorrhoids, and another had marked varicosities of both legs.
Such is the picture to be drawn from a fairly large number of renal tumors, none the less valuable because it is a composite. It shows that in spite of our best efforts we are still many laps behind the disease in the race for victory. But it also gives hope that much ground may be gained and time cut short by minute study of the symptomatology, by the intelligent use of every diagnostic procedure, and, where all else but tumor has been eliminated, by operative exploration of the kidney without delay.

$$
\text { BIBLIOGRAPHY. }
$$

Garceau: Tumor of the Kidney.

Albarran and Imbert: Les Tumeurs des Rein

Eisendrath: Jour. Amer. Med. Asso., 1900, vol. xxxiv, p 649.

Neisser and Holmer: Cited by Garceau.

Keen, P fahler and Ellis: Am. Med., 1904, vol. viii, p. 1050

Ochsner: Jour. Amer. Med Asso., vol. xxxiv, p. 649 .

Guyon: Maladies des Voies Urinaires, 1896, vol. ii, p. 260

Israel: Berl. Klin. Woch., 1899 , vol. xxvi, p. 126.

Guyon: Maladies des Voies Urinaires, 1881, p. 317

Legueu: Asso. Franc., d'Urol., 2d Sess., 1897, p. 180

Morris: Surg. Dis. of the Kidney and Ureter, vol. ii.

\section{THE EARLY RECOGNITION OF TUMORS OF THE BLADDER.*}

BY ARTHUR L. CHUTE, M.D., Boston.

THERE are many sides to the subject we are to discuss tonight, and one that I believe we may consider with profit is, "How can we get better results in our cases of tumor of the bladder?", for I believe that all who have seen and followed any considerable number of these cases will admit that their results have not been entirely satisfactory. My remarks apply only to primuary tumors of the bladder. Tumors that have their origin in the prostate and invade the bladder secondarily belong in a different group; in them the outlook is very properly considered especially unfavorable.

The means at our disposal for the treatment of bladder tumors have been added to materially within the past few years, and vary from the intravesical destruction of small papillomata, by means of cauterization, to the removal of a part or even the whole of the bladder, a very wide range of procedures and presumably adequate for the successful treatment of any primary tumor of the bladder at one time in its course.

Yet the application of these means are not always successful. Only a few days ago I saw an autopsy that illustrated this point only too well. It was on a man, for whom I had done, in October, 1911, a transperitoneal resection for a tumor situated most favorably, high in the posterior wall of the bladder. The mass had been excised with a good margin, yet it recurred, and at autopsy the whole mesentery was studded with great metastases; the bladder itself was nothing but a thick walled cavity of friable material; the os pubis was so infiltrated that it was easily cut through with a knife. Perhaps this was a case where I should have done a total cystectomy, an even more radical operative procedure than transperitoneal resection. However, my per-

* Read at the meeting of the New England Branch of the American Urological Association, Hartford, Conn., Nov. 18, 1912. 